\title{
Post-Gastric Bypass Vitamin Therapy: How Compliant are Your Patients and who is Doing the Monitoring?
}

Keywords: Morbid obesity; Vitamins; Mineral deficiencies; Gastric bypass; Compliance; Post operative monitoring

\begin{abstract}
Background: Following gastric bypass surgery, micronutrient deficiencies are a well-documented complication. Emerging evidence suggest that the replacement of these micronutrients represent an integral part of postoperative care. It is unclear whether patient's compliance with this strict regimen is applicable in all patients, as only few studies have addressed this important issue.
\end{abstract}

Patients and methods: This is a prospective case review of 235 consecutive patients who underwent laparoscopic gastric bypass between January 2005 and December 2009. All patients were instructed before surgery and during subsequent postoperative visits about compliance with vitamin supplementation.

A telephone interview was conducted to assess compliance and frequency of vitamin lab draws. Laboratory records of responders were compared with their response.

Results: 235 patients completed the interview. Mean age was 39 (range $=20-60)$, male: female $=16: 219$. About $51 \%(n=119)$ of the patients had a managed government sponsored insurance, the remaining with commercial insurance. Only $25 \%(n=59)$ of the patients reported taking all recommended vitamin supplementation, while $10 \%$ $(n=23)$ reported not taking any nutritional supplements. A further $65 \%$ $(n=153)$ were taking incomplete supplements.

In the early postoperative period, compliance was over $90 \%$. Mos defaulters stopped their supplements after 12-18 months of their surgery on average. Constipation, forgetfulness and cost of medications were the most common reasons for stopping. Most patients (54\%) obtained their laboratory tests from their primary care physician. Iron was the most common self-reported deficiency.

Conclusion: Despite adequate patient's education, compliance with micronutrient supplementation remains a major problem in post gastric bypass patients.

\section{Introduction}

With an epidemic of obesity and its associated morbidities prevalent in Western societies, an enduring weight loss program is desirable. Gastric bypass and biliopancreatic diversion fulfil this requirement as both procedures achieve weight reduction by restricting intake as well as malabsorption.

Because both procedures involve exclusion of certain portion of the gastrointestinal tract from alimentation, postoperative micronutrient deficiencies are common. These deficiencies are most severe after biliopancreatic diversion followed by long Roux limb gastric bypass. Also, micronutrient deficiencies are present in many obese patients before they embark upon their bariatric procedure. These deficiencies may persist after their surgery $[1,2]$ Emerging evidence suggest that the replacement of micronutrients

\section{Journal of Obesity and Bariatrics}

\section{Emmanuel Atta Agaba*, Kristen Smith RD, Inessa Normatov, Amandeep Singh, Sunny Change, Jenny Choi and Prathiba Vemulapalli}

Department of Bariatric Surgery, Montefiore Medical Center at Albert Einstein College of Medicine, Bronx, New York, USA

\section{*Address for Correspondence}

Emmanuel A. Agaba, MD, Department of Surgery, Montefiore Medical Center, Albert Einstein College of Medicine, Bronx, New York 10467, USA, Tel: 718-920-4800; E-mail: eagaba@gmail.com

Copyright: ( $) 2015$ Agaba EA, et al. This is an open access article distributed under the Creative Commons Attribution License, which permits unrestricted use, distribution, and reproduction in any medium, provided the original work is properly cited.

Submission: 19 February 2015

Accepted: 09 May 2015

Published: 14 May 2015

Reviewed \& Approved by: Dr. Francesco Saverio Papadia, Assistant Professor of Surgery, University of Genoa School of Medicine, Italy

deficiencies is an integral part of the postoperative care of the bariatric patient. Current recommendations suggest a regimen to include a multivitamin, $1500 \mathrm{mg}$ calcium citrate with vitamin $\mathrm{D}$, and iron. Few studies have addressed barriers to compliance and how to improve patient compliance after gastric bypass surgery. Without correction; these deficiencies may lead to severe bony, hematologic and neurologic consequences that may contribute to limiting optimal health.

Although the benefits of nutritional supplements after gastric bypass are well established, compliance however, is unpredictable and ranges from the fully compliant to the non-compliant. While the reasons for this are not well understood at present, it underscores the need for additional quality research to help us better understand the factors that lead to such a decision.

Understanding the reasons for non-compliance is often multifactorial. As suggested by two recent studies, the emotional challenges associated with the experience of bariatric surgery unfortunately may lead to major depression and suicide [3,4]. Apathy and emotional distress can cause patients to forgo follow up and compliance. Furthermore many patients who are non-compliant erroneously believe that once a satisfactory weight loss is achieved; there is no need for nutritional supplements.

There are several factors that have been shown to predict successful post gastric bypass outcome and compliance with medications. Such identifiable factors include: high self esteem, good mental status, a satisfactory marriage, high educational level, high socioeconomic status as well as strong family support. Understanding the relationship between these variables and a successful outcome will enable better patient selection and the development of intervention techniques to improve compliance. The findings in this report suggest that physicians might improve compliance through patient centered education and by taking into consideration their religious beliefs. It is unclear whether the long-term follow up of these patients is best served by their surgeon or their primary care provider. However, it is imperative that the provider is aware of these micronutrient 
Citation: Agaba EA, Kristen Smith RD, Normatov I, Singh A, Change S, et al. Post-Gastric Bypass Vitamin Therapy: How Compliant are Your Patients and who is Doing the Monitoring? J Obes Bariatrics. 2015;2(2): 5.

deficiencies and be vigilant with their specialized care.

\section{Aims}

This study was designed to assess micronutrient compliance among patients who underwent Roux Y gastric bypass (RYGBP) in our institution.

Other secondary end points include:

o To determine the extent of the problem of micronutrient deficiencies in our practice

o To identify barriers and reasons for non-compliance

\section{Patients and Methods}

This was a prospective case study of patients who underwent laparoscopic Roux Y gastric bypass between January 2005 and December 2009 in a high volume tertiary center in Bronx, New York. Patients were identified from an active clinical database of prospective clinical follow up of all bariatric surgical patients. The following variables were collated for each patient: (1) age of the patient at surgery, (2) sex, (3) ethnicity, (4) date and year of surgery, (5) type of insurance coverage, and (6) current nutritional supplement intake.

Institutional Review Board approval was obtained for this study.

Full compliance was defined as when a patient was taking iron (1 tablet/ day), Calcium citrate with Vitamin (2 Calcium Citrate with Vitamin D/ day) and multivitamin (1 Multivitamin/ day). Partial compliance was when a patient was taking any other supplement or combination of supplements other than the above. Non-compliance refers to when a patient was not taking any form of vitamin supplementation.

All patients were placed on preoperative micronutrients (1 Multivitamin tablet daily, Calcium citrate with Vitamin D 1200 mg daily, Iron with Vitamin B12 and Folic acid) two weeks before their procedures and were mandated to continue on this regimen indefinitely in their postoperative course.

In December 2010, a telephone interview was conducted of all patients who were at least one-year post RYGBP. The questionnaire consisted of 16 questions regarding current micronutrients intake, frequency of intake, laboratory assay of these micronutrients, frequency of such assay and who is monitoring the results. Additionally, comprehensive metabolic panel, complete blood count, serum iron level, hepatic panel were also assessed. Data was prospectively collated and entered into Microsoft Excel ${ }^{\circledR}$ (Microsoft Corp, Redmond Wa).

\section{Statistical Analysis}

Dataset was collated prospectively and analyzed using SPSS version 19 (Statistic Package for Social Sciences Chicago, Ill). Descriptive statistics for all study variables were obtained. Continuous variables were expressed as means and Standard deviation. In the case of non-normally distributed variables median and range were used. Categorical variables were represented as counts and percentages. Continuous variables were compared using Student's t-test or paired $\mathrm{t}$-test when appropriate. Adjustment for unequal variances was made when necessary. In the case of non-normally distributed data, Mann-
Whitney U test or Wilcoxon signed rank test was used. Categorical data were compared using the Chi squared test or Fisher's exact test as appropriate. A p-value of $<0.05$ was considered significant. The $95 \%$ Confidence Interval of the rates were calculated on the basis of the assumption that the number of events followed a normal distribution.

\section{Results}

During the study period, there were 572 laparoscopic Roux Y gastric bypasses performed on 572 consecutive patients including 90 males and 482 females. Baseline demographic characteristics are shown in Table 1 . There were 67 blacks among the responders (Table 1). Most of the responders were females.

The median age of patients at the time of their bariatric surgery was 39 years (range: 20-60) with a mean Roux limb of $150 \mathrm{~cm}$ (range 75$200 \mathrm{~cm}$ ) (Table 2). Of the 572 patients, only $41 \%(\mathrm{n}=235)$ participated in the telephone interview. Of the 235 patients who responded to the interview, compliance with micronutrient requirements was highest during the first year of surgery (Figure 1). Subsequently, this decreases (Figure 2) $(95 \%$ Confidence interval $\{\mathrm{CI}\}$ at year $5=0.07-0.67$, Odd ratio 0.22 , year $4 ; \mathrm{CI}=0.45-2.38, \mathrm{OR}=1.03$, year $3 ; \mathrm{CI}=0.75-3.73$, OR 1.68; year 2; $\mathrm{CI}=0.49-2.07, \mathrm{OR}=1.01$, year $1 ; \mathrm{CI}=1.11-7.24, \mathrm{OR}=2.84$ ) (See Figure 2). The time-specific to non-compliance was 1.54 years.

Table 1: Baseline demographic characteristics.

\begin{tabular}{|c|c|c|}
\hline \multicolumn{2}{|c|}{ Variables } & \\
\hline \multicolumn{3}{|c|}{$\begin{array}{l}\text { Age (years) : } 39 \text { (range 20-60) } \\
\text { Sex }(\mathrm{M}: \mathrm{F})=16: 219 \\
\left.\text { BMI }\left(\mathrm{Kg} / \mathrm{M}^{2}\right): 46 \text { (range } 41-67\right)\end{array}$} \\
\hline $\begin{array}{l}\text { Insurance } \\
\text { Medicare/Medicaid } \\
\text { Private }\end{array}$ & $\begin{array}{c}119 \\
116\end{array}$ & Percent \\
\hline
\end{tabular}

There were 67 blacks among the responders (Figure 1). Most of the responders were females.

Table 2: Time and reasons for stopping micronutrient supplements.

\begin{tabular}{|l|l|}
\hline $\begin{array}{l}\text { Iron } \\
\text { Time }\end{array}$ & \\
$\begin{array}{l}\text { Reason } \\
\text { Constipation/poor tolerance } \\
\text { Too expensive } \\
\text { Not important/don't need it } \\
\text { Forgetfulness }\end{array}$ & $\begin{array}{l}1.56+/-1.43 \text { years after surgery } \\
48(43)\end{array}$ \\
\hline $\begin{array}{l}\text { Calcium } \\
\text { Time }\end{array}$ & $41(47)$ \\
$\begin{array}{l}\text { Reason } \\
\text { Constipation/poor tolerance } \\
\text { Too expensive } \\
\text { Not important/don't need it } \\
\text { Forgetfulness }\end{array}$ & $5(6)$ \\
\hline $\begin{array}{l}\text { Multivitamins } \\
\text { Time } \\
\text { Reason } \\
\text { Constipation/poor tolerance }\end{array}$ & $1.40+/-1.36$ years after surgery \\
\hline Too expensive & $5(6)$ \\
\hline Not important/don't need it & $54(63)$ \\
\hline Forgetfulness & $14(16)$ \\
\hline
\end{tabular}

Parentheses are in percent

The care provider requesting the laboratory tests also affected compliance. Although, the primary care provider ordered the most tests, compliance was most common among patients whose tests were requested by their surgeon. 
Citation: Agaba EA, Kristen Smith RD, Normatov I, Singh A, Change S, et al. Post-Gastric Bypass Vitamin Therapy: How Compliant are Your Patients and who is Doing the Monitoring? J Obes Bariatrics. 2015;2(2): 5.

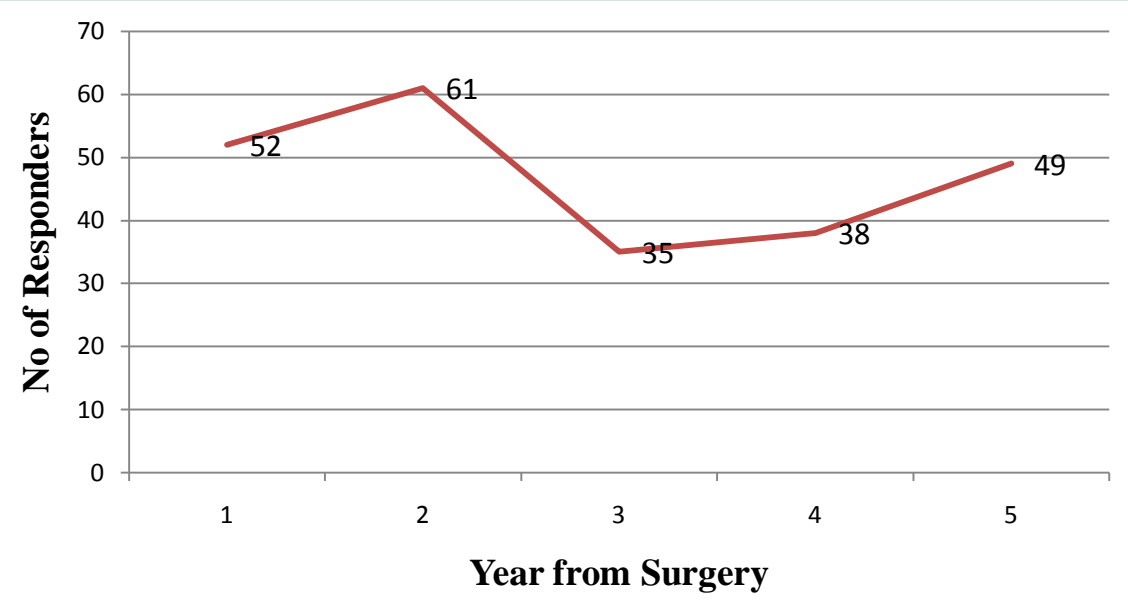

Figure 1: Micronutrient responders by year from Index Operation.

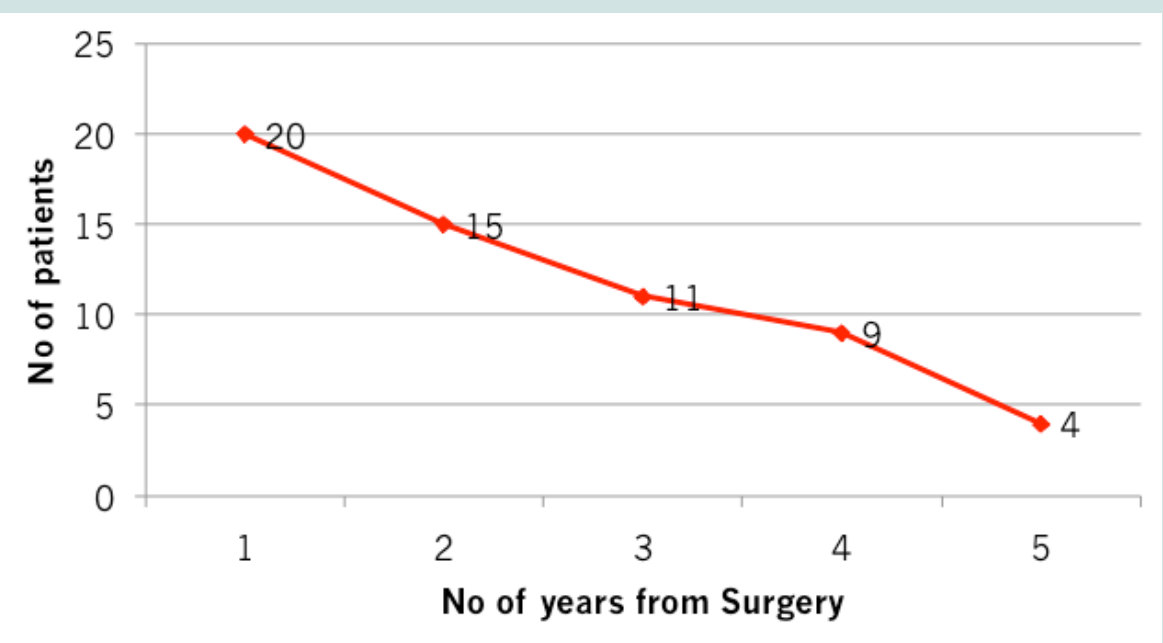

Figure 2: Compliance by year of surgery.

There were several barriers to compliance (Figure 3). Laboratory results of responders at baseline and first postoperative period were compared with their compliant status (Tables 3-6).

\section{Discussion}

Roux Y gastric bypass, a malabsorptive procedure, is associated with an increased risk of micronutrient deficiencies. While the true prevalence of these deficiencies remain unknown due to being unrecognized, misdiagnosed or underreported, mounting evidence suggest that deficiencies occur even before weight loss surgery. As several studies have shown, up to $60-80 \%$ of morbidly obese patients awaiting weight loss surgery are deficient in vitamin B12, vitamin $\mathrm{D}$, iron and other micronutrients [2,5-10]. These deficiencies may persist in the postoperative period. Published studies on metabolic deficiencies after gastric bypass have shown that $18-35 \%$ of these patients are anemic at various follow up periods. Two other studies that examined nutritional deficiencies after gastric bypass have found iron deficiency anemia in $20-49 \%$ and folate deficiency anemia in $9-18 \%$ of patients respectively $[11,12]$. In our series, laboratory profiles of responders were compared at baseline and at 1 year postoperative follow up period. Among responders, preoperative iron deficiency occurs in $11 \%$ of patients and $13 \%$ at 1 year follow up. This was comparable to previously reported series [11]. Failing to address these deficiencies may lead to serious complications such as encephalopathy, changes in bone metabolism and protein energy malnutrition.

Ensuring compliance with micronutrient supplementation is important to maintain weight loss and prevent weight regain as certain nutrients such as calcium have been shown to enhance weight loss and prevent weight regain [13].

Despite well established data that suggest that post gastric bypass patients require life-long micronutrient compliance, no guideline exist to monitor many of these deficiencies. Also, it is unclear who should be monitoring these patients and how often. Strohmayer and Crowley recommend routine screening for micronutrient deficiencies every 6 months for the first year then annually thereafter, including iron, vitamin B12, folate, vitamin D and possibly vitamin A [14,15]. 


\section{$\underline{\text { Reasons for non-compliance }}$}

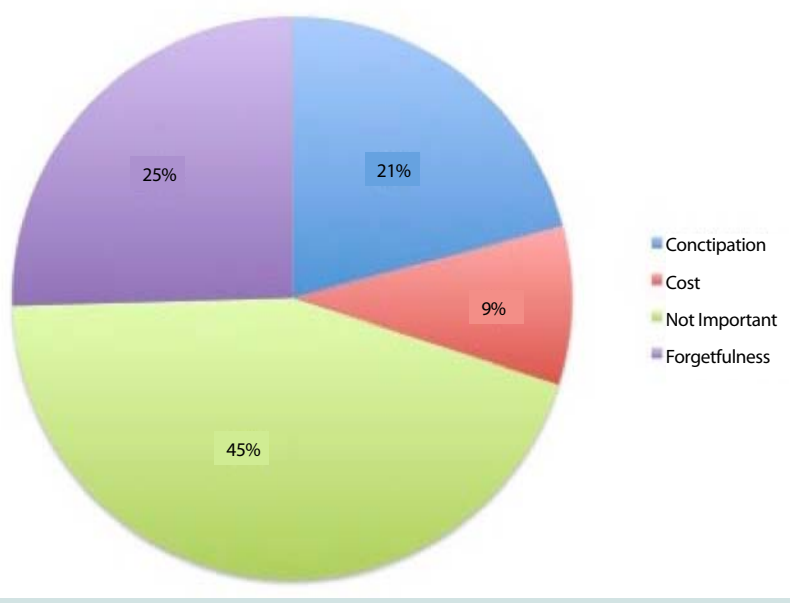

Figure 3: Reasons for non-compliance.

Table 3: Preoperative biochemical characteristics of responders.

\begin{tabular}{|c|c|c|c|}
\hline Tests & No of patients & level & Reference range \\
\hline Iron $(\mathrm{mcg} / \mathrm{dl})$ & 25 & 120 & $149-491$ \\
Ferritin $(\mathrm{ng} / \mathrm{ml})$ & 25 & 10 & $13-150$ \\
TIBC* $(\mathrm{mcg} / \mathrm{dl})$ & 25 & 600 & $149-491$ \\
Zinc & 10 & 50 & $60-120$ \\
Vitamin B1 & 15 & 7.0 & $8-30$ \\
Vitamin D25 OH & 10 & 25 & 30 \\
Vitamin B12 & 80 & 2.0 & $2.7-17$ \\
Folate & 20 & 157 & $211-946$ \\
\hline
\end{tabular}

Table 4: Biochemical characteristics of responder at first post gastric bypass year.

\begin{tabular}{|c|c|c|c|}
\hline Tests & No of patients & level & Reference Range \\
\hline Iron $(\mathrm{mcg} / \mathrm{dl})$ & 30 & 19 & $149-491$ \\
Ferritin $(\mathrm{ng} / \mathrm{ml})$ & 25 & 5 & $13-150$ \\
TIBC* $(\mathrm{mcg} / \mathrm{dl})$ & 25 & 502 & $149-491$ \\
Zinc & 15 & 48 & $60-120$ \\
Vitamin B1 & 12 & 6 & $8-30$ \\
Vitamin D25 hydroxyl & 25 & 5 & $30-80$ \\
Vitamin B12 $(\mathrm{ng} / \mathrm{ml})$ & 20 & 5 & $2.7-17$ \\
Folate $(\mathrm{ng} / \mathrm{ml})$ & 18 & 112 & $211-946$ \\
\hline Total & 100 & & 57.5 \\
\hline
\end{tabular}

TIBC: Total Iron Binding Capacity

Table 5: Relationship between laboratory testing and compliance in the first post gastric bypass year by provider.

\begin{tabular}{|l|c|c|}
\hline Provider & Lab (\%) & Compliance \\
\hline Primary care Doctor & 54 & 19 \\
Bariatric Surgeon & 43 & 38 \\
Others & 3 & 0.5 \\
Total & 100 & 57.5 \\
\hline
\end{tabular}

In our practice, we routinely adhere to this recommendation. Even when patients are compliant with their tests, it does not necessarily translate into compliance with their nutritional supplementation. In our series, laboratory results of responders were compared with their compliant status. Among patients who were fully compliant, iron deficiency occurs in 5\% of responders compared to $83 \%$ among non-compliant patients. Similarly, multivitamin deficiency occurred in $10 \%$ of fully compliant responders compared to $48 \%$ among non compliant. For this reason, it is imperative upon the bariatric surgeon, dietician and other healthcare providers to obtain a detailed nutritional history as well as recognize the signs and symptoms of micronutrient deficiencies.

Screening for micronutrient deficiencies can be done by the bariatric surgeon or by their primary care physician. Involving the primary care physician before and after surgery may enhance compliance as they may re-enforce crucial patient education and compliance.

It is unclear why some patients who stated that they were compliant with all nutritional supplements were found on testing to have iron and multivitamin deficiencies. While it is likely that these patients were reliable, it is possible that they were taking subtherapeutic doses of nutritional supplements unintentionally.

As our study has shown, most of our patients obtained their screening from their primary care provider (63\%), full compliance with micronutrient was $19 \%$. It is unclear why compliance among this group was lower than among patients whose screening was conducted by their surgeons. This unexpected low compliance rate in our series was in sharp contrast to Brolin et al. who reported a compliance rate of $64 \%$ at a mean follow up period of 24 months [16].

In most studies, compliance and follow up decrease over time, as expected. As patients lose weight and stabilize, they are more likely to self manage their care and become less compliant. The physical manifestations of malnutrition are gradual and unlikely to be noticed by patients. Since nutritional deficiencies do not present as acute problems, patients tend to underestimate the need for continued supplements, especially when there are multiple barriers. We have found that the most common reason for non-compliance was because the patients did not feel nutritional supplements was necessary. Many of the supplements have significant side effects, such as constipation, which is a major barrier to compliance. Also a significant proportion of these patients cited the cost of their nutritional supplements as a reason for their non-compliance.

Because most of our patients were on Calcium citrate preparation which is often more expensive and larger in size than its Calcium carbonate equivalent, this may have an important bearing on compliance. In our patient population where majority have

Table 6: Self reported compliance versus laboratory records.

\begin{tabular}{|l|c|c|c|c|c|c|c|}
\hline \multirow{2}{*}{ Responders } & \multirow{2}{*}{ No of Pts * } & \multicolumn{5}{|c|}{ Abnormal Laboratory results } \\
\cline { 3 - 8 } & Iron & $\begin{array}{c}\text { Vit } \\
\text { B1* }\end{array}$ & $\begin{array}{c}\text { Vit } \\
\text { B12* }\end{array}$ & $\begin{array}{c}\text { Vit } \\
\text { D3* }\end{array}$ & Zinc & Folate \\
\hline Compliance & $59\left(85^{*}\right)$ & 3 & 1 & 1 & 2 & 0 & 2 \\
Part compliance* & $153\left(50^{*}\right)$ & 8 & 3 & 4 & 6 & 2 & 2 \\
Non compliance & $23\left(20^{*}\right)$ & 19 & 8 & 15 & 17 & 13 & 14 \\
Total & 235 & 30 & 12 & 20 & 25 & 15 & 18 \\
& & & & & & & \\
\hline
\end{tabular}

*Pts: Patients; Vit: Vitamin; Part compliance: Partial compliance

Parentheses $\left({ }^{*}\right)$ : Percentage of patients with normal values, in addition to their overall number 
Citation: Agaba EA, Kristen Smith RD, Normatov I, Singh A, Change S, et al. Post-Gastric Bypass Vitamin Therapy: How Compliant are Your Patients and who is Doing the Monitoring? J Obes Bariatrics. 2015;2(2): 5.

government managed care, cost played a big factor in sustaining compliance. This finding supports the observation by Gasteyger et al. In their study examining the relationship between non-compliance with nutritional treatment and cost, Gasteyger et al. observed that at 2 years after a RYGBP, a patient in Switzerland will have spent, on average $\$ 35$ per month on nutritional supplements [17]. An additional $\$ 360$ per patient per sample is spent on extensive biological nutritional assessment in Lausanne, Switzerland. The group concluded that taking several pills per day is a problem for many patients, and the cost of treatment is probably a major barrier to adequate compliance. Involving social workers early to address financial issues that may have contributed to non-compliance may be a useful approach to curbing noncompliance due financial hardship. Psychiatric referral for further counseling and evaluation may be necessary in some patients.

Although we have not specifically addressed the issue of missed preoperative appointments in our study, others who have examined this issue observed that it correlates with postoperative noncompliance $[18,19]$. The lack of consensus on this issue can be linked to the lack of research on post surgical weight loss and the inherent issues with micronutrient compliance [20]. Several factors that may be associated with noncompliance include age and distance from follow up clinic. In the study conducted by Jenkins et al. compliance with follow-up decreases from $94 \%$ at 6 months to $69 \%$ in 2 years in adolescent [21].

In the Jenkins et al. study examining the impact of distance from clinic on follow up and nutritional supplementation observed that distance does not appear to affect compliance. On the other hand, Lara et al. observed that distance was an important factor after 9 months [22].

\section{Conclusion}

Compliance with micronutrient supplementation after gastric bypass is a major issue in the after care of bariatric patients. Many barriers to continued compliance exist, such as cost, side effects, lack of education and counseling and poor follow-up. Continuing education and post-operative follow up is necessary and critical in preventing and detecting nutritional deficiencies. Primary care physicians may play an important role in further reinforcing, educating and monitoring post bariatric patients. Collaboration between bariatric surgeons and primary care physicians may be the key to ensuring patient compliance post bariatric surgery.

\section{References}

1. Gehrer S, Kern B, Peters T, Christoffel-Courtin C, Peterli R (2010) Fewer nutrient deficiencies after laparoscopic sleeve gastrectomy (LSG) than after laparoscopic Roux-Y-gastric bypass (LRYGB): a prospective study. Obes Surg 20: 447-453.

2. Flancbaum L, Belsley S, Drake V, Colarusso T, Tayler E (2006) Preoperative nutritional status of patients undergoing RouX-en-Y gastric bypass for morbid obesity. J Gastrointest Surg 10: 1033-1037.

3. Omalu BI, Ives DG, Buhari AM, Lindner JL, Schauer PR, et al. (2007) Death rates and causes of death after bariatric surgery for Pennsylvania residents, 1995 to 2004. Arch Surg 142: 923-928.
4. Adams TD, Gress RE, Smith SC, Halverson RC, Simper SC, et al. (2007) Long-term mortality after gastric bypass surgery. N Engl J Med 357: 753-761.

5. Buffington C, Walker B, Cowan GS Jr, Scruggs D (1993) Vitamin D deficiency in the morbidly obese. Obes Surg 3: 421-424.

6. Carlin AM, Rao DS, Meslemani AM, Genaw JA, Parikh NJ, et al. (2006) Prevalence of vitaminosis $D$ depletion among morbidly obese patients seeking gastric bypass surgery. Surg Obes Relat Dis 2: 98-103.

7. Ybarra J, Sánchez-Hernández J, Gich I, De Leiva A, Rius X, et al. (2005) Unchanged hypovitaminosis D and secondary hyperparathyroidism in morbid obesity after bariatric surgery. Obes Surg 15: 330-335.

8. Reitman A, Friedrich I, Ben-Amotz A, Levy Y (2002) Low plasma antioxidants and normal plasma $B$ vitamins and homocysteine in patients with severe obesity. Isr Med Assoc J 4: 590-593.

9. Boylan LM, Sugerman HJ, Driskell JA (1988) Vitamin E, vitamin B6, vitamin B12 and folate status of gastric bypass surgery patients. J Am Diet Assoc 88: 579-585

10. Madan AK, Orth WS, Tichansky DS, Ternovits CA (2006) Vitamin and trace mineral levels after laparoscopic gastric bypass. Obes Surg 16: 603-606

11. Halverson JD, Zuckerman GR, Koehler RE, Gentry K, Michael HE, et al. (1981) Gastric bypass for morbid obesity: a medical- surgical assessment. Ann Surg 194: 152-160

12. Brolin RE, Gorman JH, Gorman RC, Petschenik AJ, Bradley LJ, et al. (1998) Are vitamin B12 and folate deficiency clinically important after roux-en-Y gastric bypass? J Gastrointest Surg 2: 436-442.

13. Allied Health Sciences Section Ad Hoc Nutrition Committee, Aills L, Blankenship J, Buffington C, Furtado M, et al. (2008) ASMBS Allied Health Nutritional Guidelines for the surgical weight loss patient. Surg Obes Relat Dis 4: $\mathrm{S} 73-\mathrm{S} 108$

14. Strohmayer E, Via MA, Yanagisawa R (2010) Metabolic management following bariatric surgery. Mt Sinai J Med 77: 431-445.

15. Crowley LV, Seay J, Mullin G (1984) Late effects of gastric bypass for obesity. Am J Gastroenterol 79: 850-860.

16. Brolin RE, Gorman RC, Milgrim LM, Kenler HA (1991) Multivitamin prophylaxis in prevention of post-gastric bypass vitamin and mineral deficiencies. Int $J$ Obes 15: 661-667.

17. Gasteyger C, Suter M, Gaillard RC, Giusti V (2008) Nutritional deficiencies after Roux-en-Y gastric bypass for morbid obesity often cannot be prevented by standard multivitamin supplementation. Am J Clin Nutr 87: 1128-1133.

18. Toussi R, Fujioka K, Coleman KJ (2009) Pre- and postsurgery behavioral compliance, patient health, and postbariatric surgical weight loss. Obesity (Silver Spring) 17: 996-1002.

19. Elkins G, Whitfield P, Marcus J, Symmonds R, Rodriguez J, et al. (2005) Noncompliance with behavioral recommendations following bariatric surgery. Obes Surg 15: 546-551.

20. Lier HØ, Biringer E, Stubhaug B, Eriksen HR, Tangen T (2011) Psychiatric disorders and participation in pre- and postoperative counselling groups in bariatric surgery patients. Obes Surg 21: 730-737.

21. Jenkins TM, Xanthakos SA, Zeller MH, Barnett SJ, Inge TH (2011) Distance to clinic and follow-up visit compliance in adolescent gastric bypass cohort. Surg Obes Relat Dis 7: 611-615.

22. Lara MD, Baker MT, Larson CJ, Mathiason MA, Lambert PJ, et al. (2005) Travel distance, age, and sex as factors in follow-up visit compliance in the post-gastric bypass population. Surg Obes Relat Dis 1: 17-21. 